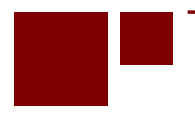

C E N T E R for RETIREMENT RES E A R C H at BOSTON COLLEGE

\title{
HOW DO PEOPLE DECIDE ON LIFE INSURANCE AND LONG-TERM DISABILITY INSURANCE COVERAGE?
}

\author{
Norma B. Coe and Anek Belbase
}

CRR WP 2015-4

Released: June 2015

\author{
Center for Retirement Research at Boston College \\ Hovey House \\ 140 Commonwealth Avenue \\ Chestnut Hill, MA 02467 \\ Tel: 617-552-1762 Fax: 617-552-0191 \\ http://crr.bc.edu
}

Norma B. Coe is an assistant professor of health services at the University of Washington. Anek Belbase is a research project manager at the Center for Retirement Research at Boston College. The research reported herein was pursuant to a grant from Prudential Financial. The findings and conclusions expressed are solely those of the authors and do not represent the views of Prudential Financial, the University of Washington, or Boston College. The authors would like to thank Greenwald and Associates for its assistance in constructing the interview scripts and carrying out the interviews. They are also grateful to Madeline Medenica for research assistance. All errors are their own.

(C) 2015, Norma B. Coe and Anek Belbase. All rights reserved. Short sections of text, not to exceed two paragraphs, may be quoted without explicit permission provided that full credit, including (C) notice, is given to the source. 


\begin{abstract}
About the Center for Retirement Research
The Center for Retirement Research at Boston College, part of a consortium that includes parallel centers at the University of Michigan and the National Bureau of Economic Research, was established in 1998 through a grant from the Social Security Administration. The Center's mission is to produce first-class research and forge a strong link between the academic community and decision-makers in the public and private sectors around an issue of critical importance to the nation's future. To achieve this mission, the Center sponsors a wide variety of research projects, transmits new findings to a broad audience, trains new scholars, and broadens access to valuable data sources.
\end{abstract}

Center for Retirement Research at Boston College

Hovey House

140 Commonwealth Ave

Chestnut Hill, MA 02467

Tel: 617-552-1762 Fax: 617-552-0191

http://crr.bc.edu

Affiliated Institutions:

The Brookings Institution

Massachusetts Institute of Technology

Syracuse University

Urban Institute 


\section{Introduction}

The group benefits landscape is changing dramatically. The menu of available options has grown; employers are paying for fewer benefits; and the responsibility for selecting the benefit package has been increasingly left to the employee. However, unlike in the pension world, very little is known about how employees select their benefits packages, if their selections are optimal for their situations, or what employers can do to encourage the optimal selection of benefits packages. In a changing benefit landscape, it is important to determine three things: (1) What are current employer practices and their resulting take-up and coverage patterns?; (2) Which practices influence employees' selections?; and (3) What can employers do to make employees' selections closer to the employees' optimal choices?

This first analysis allows us to peer into the black box of employee decision-making and identify what behavioral finance concepts are at play in the group benefits arena. Using information from 24 in-depth telephone interviews, we gain important insight into how employees determine whether to buy supplemental life and supplemental long-term disability insurance, how they decide how much to buy, what they liked and understood from their employers' presentations, and what features might make these insurance benefits more appealing to individuals.

This report proceeds as follows. Section 1 discusses the methodology for the interviews and the characteristics of the survey pool. Section 2 discusses life insurance purchases, and Section 3 focuses on long-term disability insurance purchases. Section 4 concludes that, despite the similarities between life and long-term disability insurance, the decision processes for buying each product vary dramatically. The need for life insurance is apparent, but individuals have a harder time determining how much insurance they need and tend to rely on rules of thumb. The need for disability insurance is much less clear, and thus it is infrequently purchased. Individuals do not understand disability incidence or the insurance product or how disability insurance interacts with governmental disability insurance programs. But even simple conversations about disability and disability insurance show promise in changing common misperceptions about need and provide a very interesting avenue to pursue in future work.

\section{Methodology and Data}

To begin our investigation of how households decide on life and disability insurance coverage, we partnered with Greenwald \& Associates to conduct a series of in-depth telephone 
interviews with consumers regarding their choices of whether to purchase voluntary life or disability benefits available to them through their workplace. The interviews explored how these insurance benefits are presented to employees, what features attract buyers, and what barriers exist for those who elected not to purchase the coverage. Consumers are also asked about their perceptions of the adequacy of their life and disability insurance and how this compares to assessments of their health, auto, or homeowners insurances.

In order to explore decision-making in the context of behavioral economics, the questioning attempted to uncover:

- How consumers perceive the threat of death and disability - the likelihood of experiencing these events and the financial consequences associated with each;

- The perceived adequacy of insurance in mitigating the financial consequences of death and disability;

- Mental accounting and other shortcuts consumers use to value insurance coverage.

The respondents are a balanced mix of men and women, parents and those without children, primary breadwinners and working spouses of primary breadwinners, and those who had purchased voluntary coverage and those who had not. Additional screening criteria include:

- Employer must offer either voluntary life or disability coverage, regardless of whether or not these products were purchased by the respondent;

- Age 21 or older;

- Employed full-time;

- Household incomes between $\$ 10,000$ and $\$ 249,999$;

- At least somewhat involved in making household financial decisions.

Professional interviewers at Greenwald \& Associates conducted the telephone interviews between December 2011 and March 2012. Nearly all of the interviews took place in the evening and lasted approximately 45 minutes. The interview script appears in Appendix A.

Table 1 outlines the descriptive statistics of the sample and a sub-sample of parents. ${ }^{1}$ Nearly all of the respondents are married and most had children. The largest share has household incomes between $\$ 50,000$ and $\$ 150,000$ and household assets between $\$ 50,000$ and

\footnotetext{
${ }^{1}$ Additional comparisons were made by sex, but men and women responded very similarly to this exercise.
} 
$\$ 200,000$. The parents in our sample have slightly lower net worth than the overall sample and, as such, report being more likely to live paycheck-to-paycheck, as opposed to having a rainy day fund or saving on a regular basis. At the same time, the parents in our sample exhibit signs of being more risk averse, as shown by their lower reported probability of taking high deductible auto and health insurance plans.

\section{Life Insurance}

The Purchase Decision. The first step is to determine how employees decide whether they would purchase life insurance. Figure 1 illustrates that they do not spend much time deliberating their needs. Over 40 percent of the sample spends less than 30 minutes thinking about their life insurance purchases. However, there seems to be little need to convince people that they need life insurance. As one respondent put it, life insurance is "almost required, or at least highly recommended" and something "most people have."

All respondents have supplemental life insurance offered through their employers. Almost half of the sample purchase additional coverage through work and just over half purchase it via an alternative source, such as a previous employer, individual market, or union.

Further, individuals do not often revisit their life insurance decision, as illustrated in Figure 2. Most state that they do not think about it often, though about one-quarter of the sample indicates that they think about it during the annual benefit renewal. Individuals also think about life insurance when one would expect them to: when they start a job, when the employer policy changes, and with good news in their life (marriage, children).

Employer Roll-Out Practices. Overall, individuals are fairly pleased with employer presentations of life insurance benefits. Almost 70 percent receive a presentation by someone in their human resources department; those with an HR representative are more likely to report they trust the source (80 percent vs. 60 percent of those who are not presented their benefit by an HR representative). The interviewees note that HR representatives do not give advice or personalized information, but they report that their reps do seem knowledgeable about the benefits package. Although some say they would like personalized advice, few - even some of those reporting it would be nice - avail themselves of that service when their employer provides it. 
Many indicate that the benefit of payroll deductions and the prices of the policies make buying through the employer convenient. Less than one-third, however, actually compares prices. For those who did compare prices, they often compare with a previous employer's price, a price offered through a union, or a previous conversation with an agent. For those who do not compare prices, they often still feel that the employer is offering a good deal or discount. This assessment could be partly due to the fact that the premiums in the employer-sponsored realm are quoted per paycheck, which makes the premium seem small. Policies purchased elsewhere are quoted in annual terms.

How Much to Purchase. While the need for life insurance seems widely understood, an adequate level of benefits remains more of a mystery to potential purchasers. Very few discuss this matter with family (about one-quarter) or co-workers, or seek professional advice. Over half of the sample said expert advice would be of interest, yet many do not use advice made available to them during the benefit roll-out period. The keys to whether employees want expert advice are whether the advice can be customized to the individual's situation and the perceived trustworthiness of the source.

While the time spent making the decision is relatively short, the survey suggests that many people are engaged in well-defined mental accounting. Over 40 percent of the sample indicate that in their budgetary framework, they first decide on how much they need to spend on other necessities - including health and auto insurance - before determining how much they have left to buy life insurance, as illustrated in Figure 3. Individuals in this category are also more likely to report that they are not adequately insured or are less likely to have supplemental life insurance. The same percent of respondents indicate that they decide how much life insurance they need and then buy the right coverage. Finally, only 11 percent indicate that they decided how much to purchase based on what "feels right."

Since life insurance is framed as a lump-sum payout (or future asset), most interviewees indicate that, in determining how much coverage they wanted, they think about big-ticket items (future liabilities) they would want their family to be able to pay off upon their death. Within this framework, easily recallable items like the monthly mortgage are more likely to be considered than less obvious expenses like retirement savings. Figure 4 illustrates the majority chose paying off the mortgage, while almost half want to insure their children's college tuition. 
Virtually no one states that their determination process takes into account maintaining the families’ lifestyle or continuing to save for the surviving spouse’s retirement.

Potential Variations. The interviews offered hypothetical variations on the current life insurance policy, such as including reward points, changing the payout stream, or pairing life insurance with other insurance policies. Overall, respondents show little interest in changing the current policy format, perhaps since individuals seem to understand what they are purchasing. For example, loyalty points or rewards do not seem to hold much value. While some indicate they like this idea, these individuals view points as a vehicle for discounts and lower prices, which are of interest to everyone. Others are concerned that the rewards seemed gimmicky and that they might actually increase premiums.

Almost half of the individuals interviewed express interest in receiving the payout in an annuity stream instead of a lump sum. The choice does not seem to depend on the level of confidence in the individual left to manage the money. Instead, their views of the preferred payment stream are tied to what they want their survivors to do with the money. A lump sum is preferred only if they want their survivors to exclusively pay off debt and meet significant financial goals; the annuity is of interest if they want to help their survivors with living expenses.

Some have a potential interest in financial counseling for the survivors. This interest does not strongly correlate with the desire for an annuity or a lump-sum payout. Some individuals want to know who would be doing the financial counseling, indicating a distrust if the insurance company were to provide the service and try to sell more products to the family. Many indicate that financial counseling would be a benefit to others, but would not be of particular interest to them or their beneficiaries.

\section{Long-Term Disability Insurance}

The Purchase Decision. In contrast to life insurance, many individuals fail to recognize the need for long-term disability insurance. While many individuals report having experience with disability - either through their own employment (a rehabilitation nurse), a family member, or their own recent disability event - almost everyone reports being less likely than average to become disabled during their lifetimes. Overall their justification of this belief is lifestyle choice - they are not dare devils, they do not smoke, and they generally take good care of themselves. 
Perhaps because they perceive less risk of a disabling event, they do not report triggers that cause individuals to think about or revisit their disability insurance purchase decisions. Almost two-thirds of the sample spend less than 30 minutes before deciding not to buy the coverage; a full 30 percent report never reconsidering this decision (Figures 1 and 2).

Individuals perceive the probability of becoming disabled as minimal, likely due to their definition of disability. Their perception of long-term disability is a catastrophic injury or illness, a “destitute state.” They never see themselves as unable to work or disabled forever, instead indicating that they would want to recover, return to work, or always have hope of doing so. Two things are going on. First, an individual's definition of the payout state is narrow and improbable. Individuals state surprise when discussing the fact that disability could cover illnesses such as cancer, where the treatment period is relatively long, the possibility of recovering is relatively high, but may not be covered by sick leave policies. Second, because individuals always want to maintain the hope of returning to work, they are turned off by longterm disability insurance, because it is presented in a way that talks about lifetime incapacity, instead of as a way to help them get back on their feet. ${ }^{2}$ Finally, people express a willingness to rely on others - family or the government - in the event of disability, which also reduces their perceived need for insurance.

However, while they perceive disability as a low-chance event, they do report that, should it occur, they would experience serious financial consequences. Figure 5 shows that 7080 percent of our sample feels that their death would be financially manageable for their dependents. Although this perception does not vary significantly within the sample, there is interesting variation in the perceived adequacy of insurance against a long-term disability. Men are the most confident, with one-third indicating that their disability would be financially manageable; women and parents are less confident, with just over half feeling their disability would be financially manageable.

The good news is that the survey provides indications that small interventions could be enough to encourage individuals to think about disability insurance. One respondent said the interview prompted her to think about her disability needs in a new light.

\footnotetext{
${ }^{2}$ In general, there was some confusion about short-term versus long-term disability benefits. It is worth noting that many people commented that their employers paid for short-term disability but did not pay for long-term disability, which may also be providing a signal to the individual of the relative importance of the two insurance products.
} 
Employer Roll-Out Practices. About half of the sample said that an HR individual presented the disability insurance policy; the other half reported that an insurance representative did the presentation. Two-thirds reported having an Internet-only option for signing up and getting information; the remaining third is split evenly between paper-only and both Internet and paper options. Individuals overwhelmingly reported trusting their sources of information.

How Much to Purchase. Since the need for disability insurance is not obvious, it is even harder for individuals to decide how much to purchase. Unlike in the case of life insurance, individuals are often confused about what the disability insurance policy is - what conditions it covers, what the benefit amount is, and why the price is "so high."

The ability to decide how much disability insurance to buy is hindered by a lack of understanding about the benefits they will get in the unlikely event of a disability. They are vaguely aware of other disability programs that are "free" - Social Security disability, short-term disability, worker's compensation, and veteran's benefits. They do not understand what the "70 percent" policy means in terms of take-home pay. Many indicate that 70 percent of their salary is not enough to live on, so they do not see the need to purchase expensive insurance with an inadequate benefit.

Since individuals narrowly define the payoff state and do not understand the benefit, disability insurance appears very expensive. Since they do not tend to have outside price indicators, they use other price points in their group benefits package, such as health and life insurances. They understand the relatively high price of health insurance, but do not understand the relatively high price of disability insurance compared with life insurance.

Potential Variations. It is interesting to note that individuals who overwhelming reject buying disability insurance through their employers are very interested in potential variations on the current policy. Figure 6 illustrates the popularity of several options. The options are combined into three broad categories: price, benefit framing, and combining products.

Price. Loyalty rewards are fairly popular, with over 75 percent reporting interest. This response strengthens the notion that disability insurance is perceived as simply too expensive.

Benefit Framing. It is clear that individuals do not understand the benefits they would get from disability insurance. Adding prevention programs to disability coverage - a benefit they 
can see and experience more frequently than a disabling event - appeals to many. Also, reframing the benefit to be a lower percentage of pay and as a top-up policy to the other disability programs appears attractive. This option would allow individuals to understand their benefit and how it interacts with the public programs they are vaguely familiar with, without doing any of their own research. Receiving payments in a lump-sum, instead of an annuity, is not attractive. However, everyone indicates that home health care would be an attractive feature of the policy. This finding again speaks to the fact that individuals do not understand how they would use their disability benefit or how far their benefit would go in covering expenses.

Combining Products. Individuals are open to the idea of bundling long-term disability insurance with other insurance products they currently purchase. Since bad health shocks and car accidents are the most likely perceived methods of becoming disabled, individuals are most receptive to bundling with health and auto insurance. A close third is the idea of bundling life insurance and disability insurance together as an "income-insurance” policy, though some respondents were concerned about what bundling would do to the price. This reaction highlights the fact that life insurance is perceived as inexpensive relative to the value they place on the benefit, and disability insurance relatively expensive.

\section{Conclusions}

These in-depth interviews reveal a lot about how individuals make decisions about voluntary life and disability insurance purchases. Importantly, the interviews also highlight several barriers that prevent individuals from getting adequate coverage.

For life insurance, the need for insurance is clear in people's minds. They do not spend a lot of time on the decision but do revisit it occasionally, often prompted by the annual sign-up process or when good things happen in their life, such as marriage or childbirth. However, individuals have a difficult time calculating how much life insurance coverage they should have. They largely rely on anchors - the employer default, the big-ticket items they are concerned about paying, or an agent recommendation - and adjust from there. Further, they are likely to ignore income replacement needs. This process could be due to the benefit being framed as a lump sum, causing individuals to focus on the lump-sum uses of the death benefit, overlooking its annuity-type uses. 
Since the right amount of coverage is difficult to calculate, some individuals rely on the price to determine how much life insurance to buy. They are largely unaware of "fair" prices, and they instead compare the price offered by their current employer to prices offered by previous employers or prices for other items in the group benefit package. In this way, life insurance appears very inexpensive. This perceived affordability leads individuals to decide on how much life insurance to buy based on a "painless amount" per paycheck or on framing it in terms of a foregone coffee or dinner out. This line of thinking is not helpful in persuading individuals to buy adequate insurance.

While disability insurance may be similar to life insurance, the decision processes people use concerning coverage is different. First and foremost, individuals do not perceive the need for disability insurance. They define disability narrowly and perceive their risk of being in that state as very unlikely and, for the most part, under their control. Individuals are also very optimistic about recovery for any disease or disability that might befall them.

Further, individuals do not understand disability insurance policies. They know about other disability programs - workman's compensation, Social Security, short-term disability through the employer - and do not understand the value-added of a long-term disability policy. Many individuals do not understand the disabling conditions for which long-term disability insurance would pay. The framing of the benefit as 70 percent of salary does not translate well into what their actual income and outlays would be should something occur; they do not understand whether this is in addition to, or instead of, these other ("free") programs.

The results of this survey suggest several avenues to pursue. The responses reveal some of the major obstacles in getting individuals to choose adequate insurance policies, and the challenge now lies in identifying ways to remove these obstacles. For life insurance, the major problem is getting individuals to assess how much coverage they need. Testing online calculators that include the cost of replacing big-ticket items (like a car or house), providing anchors other than the employer's 1-times-salary contribution, and changing the framing of the benefit seem like fruitful avenues of future work. For disability insurance, the major problem is getting individuals to assess any need. Simple education programs about the definition of disability, frequency of disability, and being more explicit about the value of the disability insurance benefit are important next steps. 
Table 1. Descriptive Statistics about the Interviewees

\begin{tabular}{lrr}
\hline & $\begin{array}{c}\text { Total } \\
\mathrm{N}=24\end{array}$ & $\begin{array}{r}\text { Parents } \\
\mathrm{N}=17\end{array}$ \\
\hline Demographic Characteristics & & \\
Married & $87.5 \%$ & $94.4 \%$ \\
Average number of dependents & 3.4 & 3.9 \\
Male & $52.2 \%$ & $55.6 \%$ \\
Have children & $78.3 \%$ & $100.0 \%$ \\
Average number of children & 1.9 & 2.1 \\
Age & & \\
$\quad 21-30$ & & \\
$\quad 31-40$ & $8.3 \%$ & \\
$\quad 41-50$ & $29.2 \%$ & \\
$50+$ & $29.2 \%$ &
\end{tabular}

\section{Financial Characteristics}

Household income

$\$ 10,000-\$ 49,999$

$12.5 \%$

$\$ 50,000-\$ 74,999$

$25.0 \%$

$\$ 75,000-\$ 99,999$

$25.0 \%$

$\$ 100,000-\$ 149,999$

$37.5 \%$

$\$ 150,000-\$ 199,999$

$0.0 \%$

$\$ 200,000-\$ 249,999$

$0.0 \%$

Net worth

under $\$ 20,000$

$\$ 20,000-\$ 49,999$

$4.3 \% \quad 5.9 \%$

$\$ 50,000-\$ 99,999$

$8.7 \% \quad 5.9 \%$

$\$ 100,000-\$ 199,999$

$30.4 \% \quad 29.4 \%$

\$200,000-\$349,999

$21.7 \% \quad 29.4 \%$

\$350,000-\$99,999

$13.0 \% \quad 11.8 \%$

$\$ 500,000-\$ 749,999$

$8.7 \% \quad 11.8 \%$

$\$ 750,000-\$ 999,999$

$8.7 \% \quad 5.9 \%$

$\$ 1$ million or more

$0.0 \% \quad 0.0 \%$

$4.3 \% \quad 0.0 \%$

Paycheck-to-paycheck

$36.4 \% \quad 38.9 \%$

Risk aversion

High deductible auto

High deductible health

$47.4 \% \quad 38.9 \%$

$26.3 \% \quad 16.7 \%$

\section{Life Insurance}

Offered life insurance

$100.0 \% \quad 100.0 \%$

Purchased life insurance through work

$45.8 \% \quad 45.8 \%$

Purchased life insurance on own

$58.3 \%$

\section{Disability Insurance}

Offered long term disability insurance

$79.2 \% \quad 79.2 \%$

Purchased long term disability insurance through work

$17.4 \% \quad 11.1 \%$

Purchased long term disability insurance on own

$0.0 \% \quad 0.0 \%$ 
Figure 1. How Long Did You Think About the Purchase?

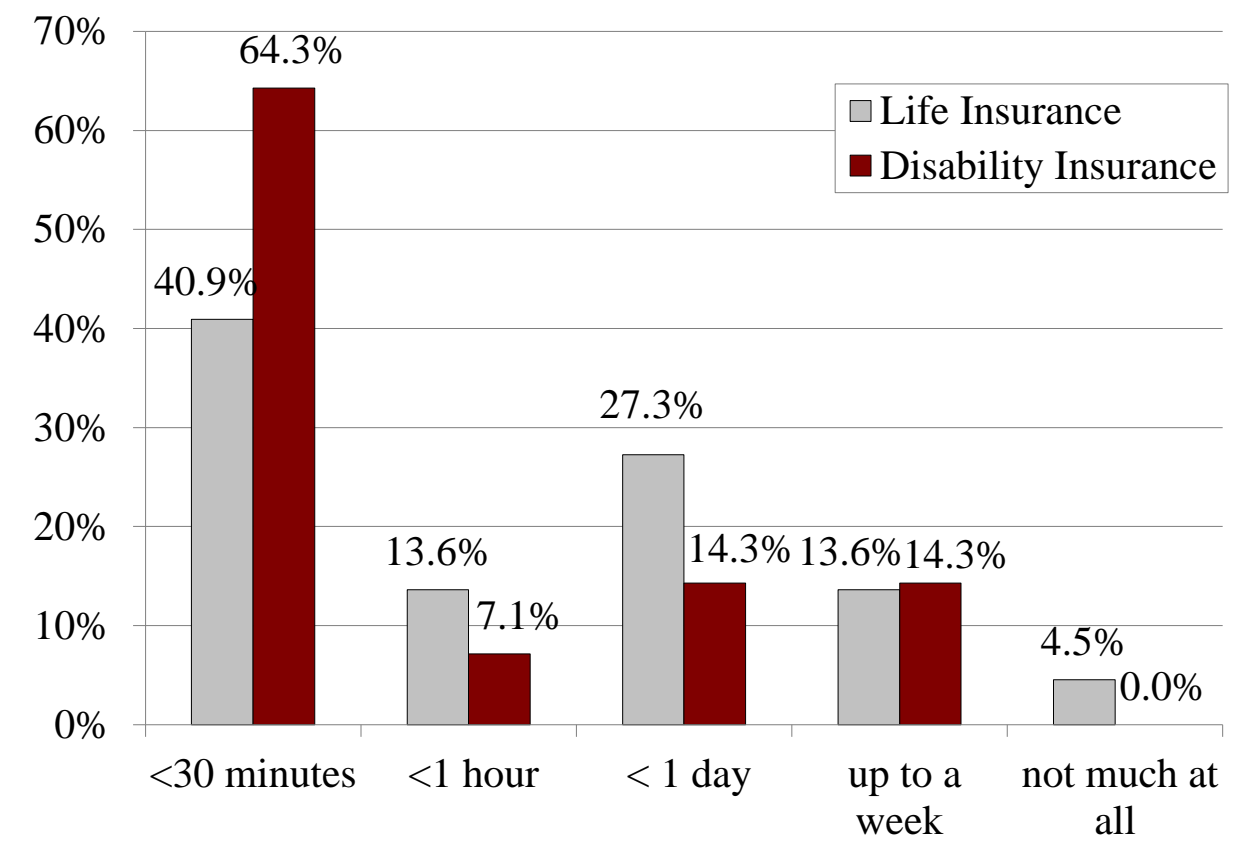

Figure 2. How Often Do You Think About Your Purchase?

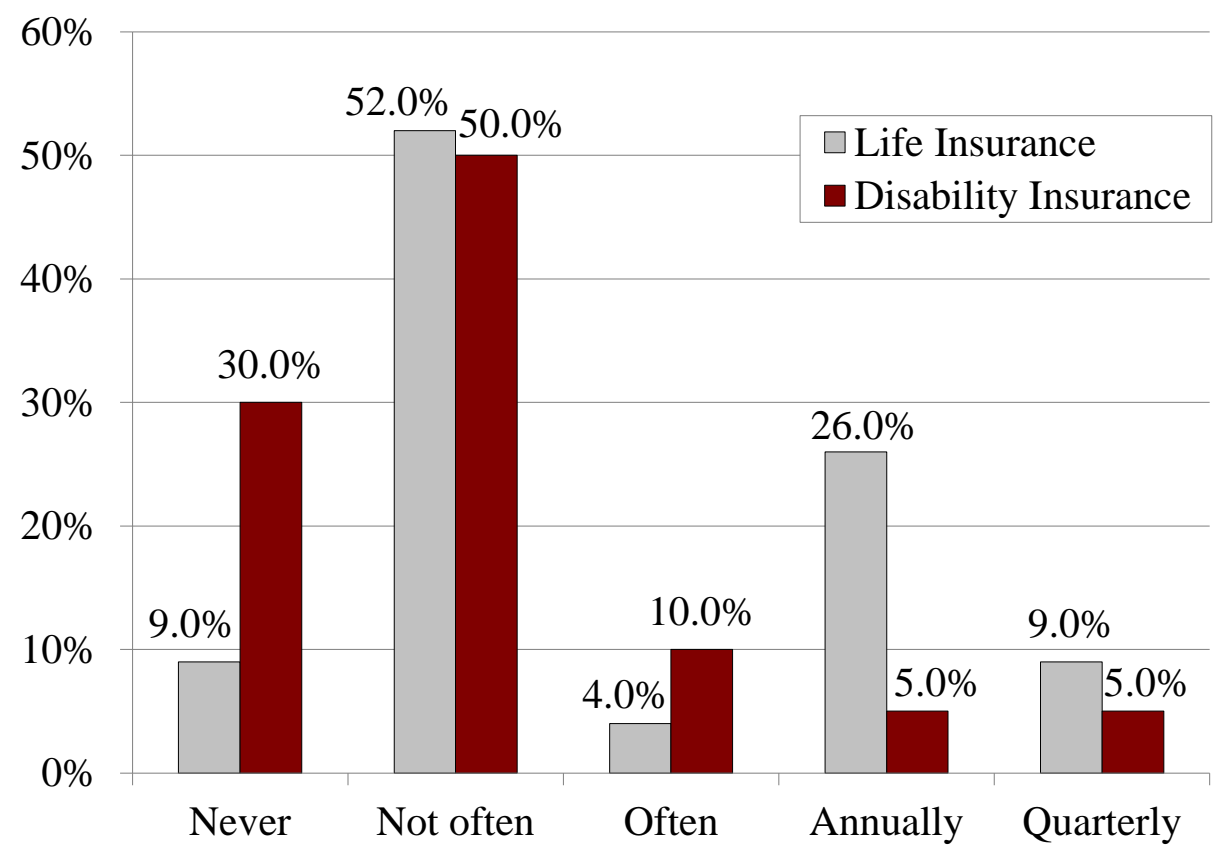


Figure 3. Life Insurance: How Do You Budget?

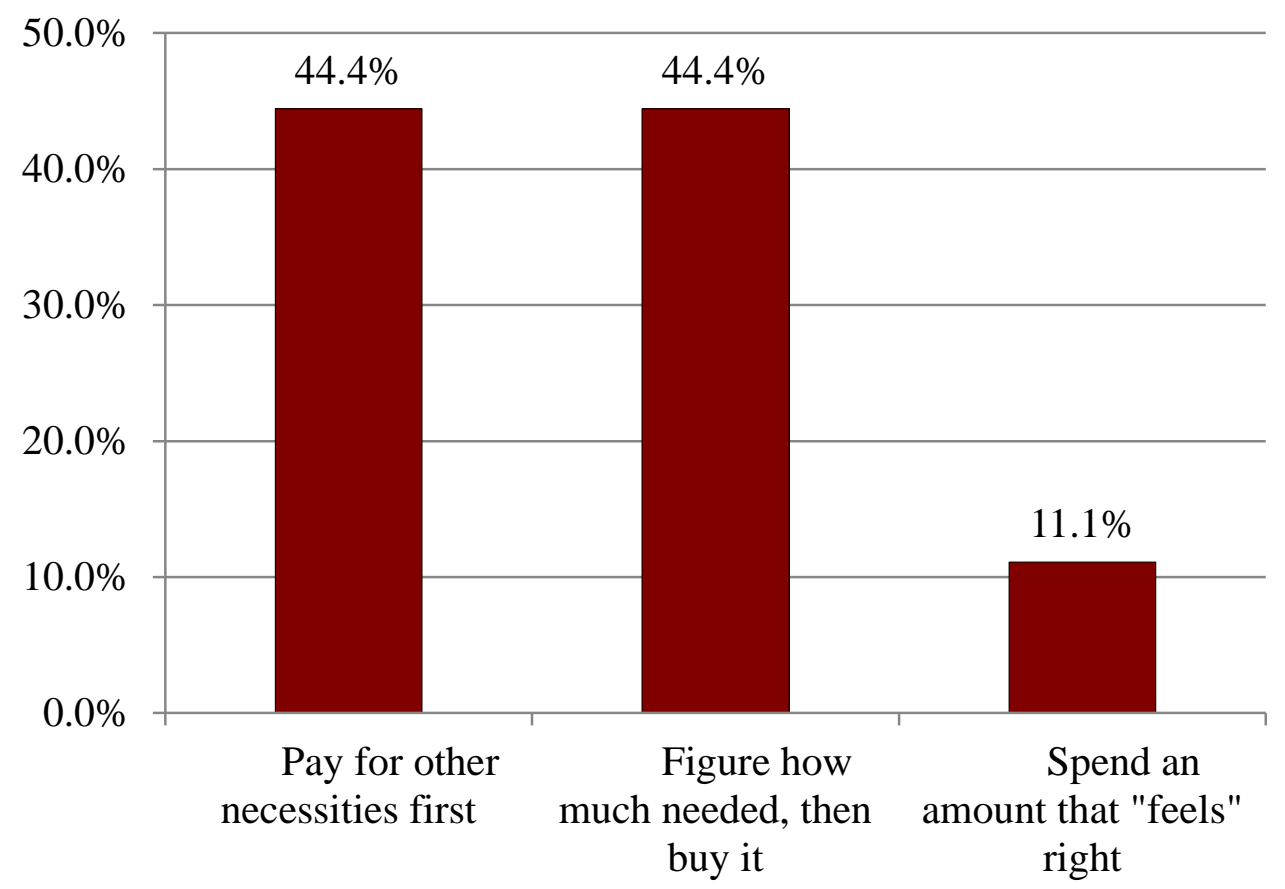

Figure 4. What Big Ticket Items Do You Use to Calculate How Much Life Insurance You Need?

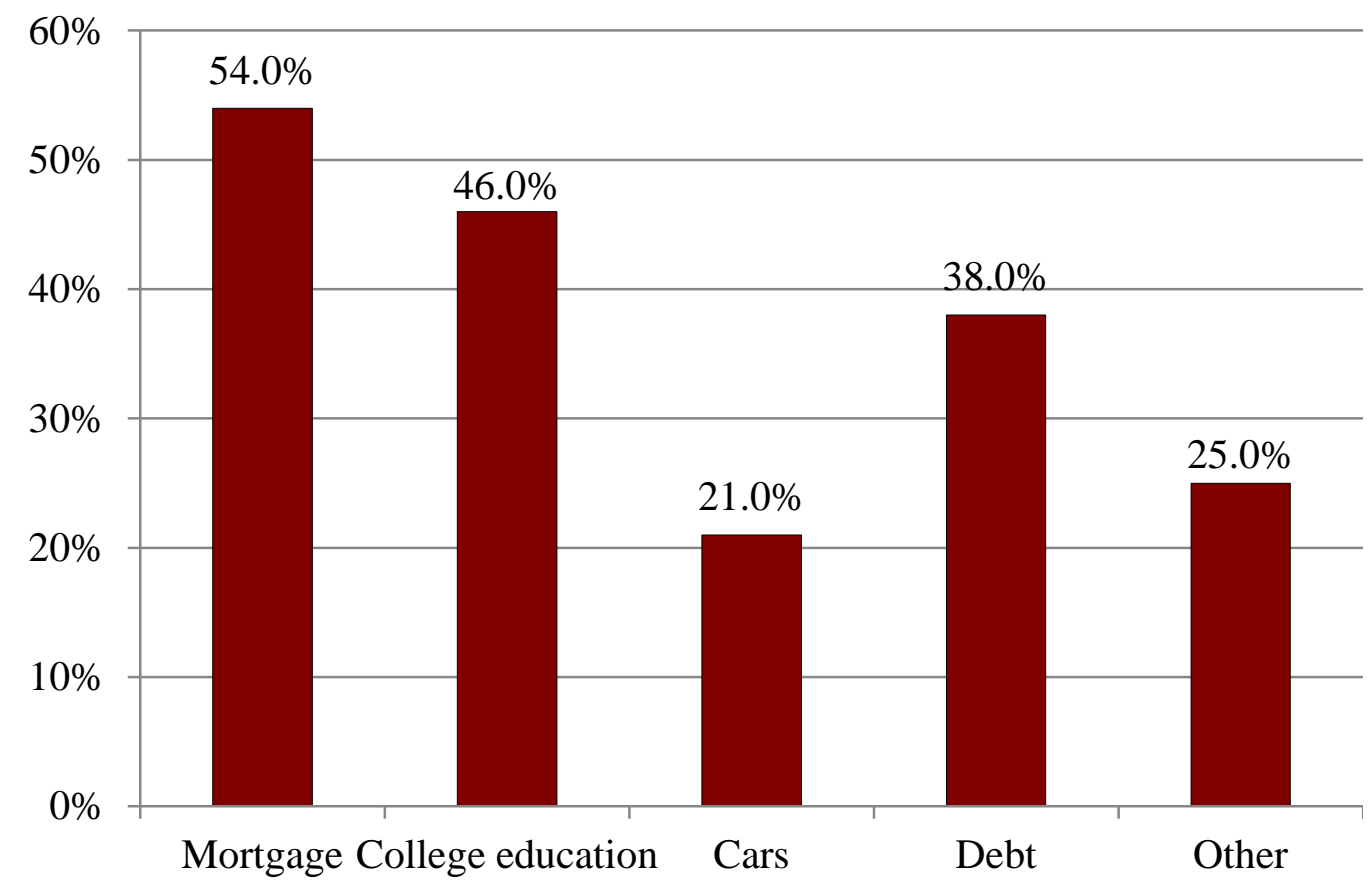

Note: Since individuals could indicate more than one item, the percentages sum to more than 100. 
Figure 5. Would Death/Disability Be Financially Manageable?

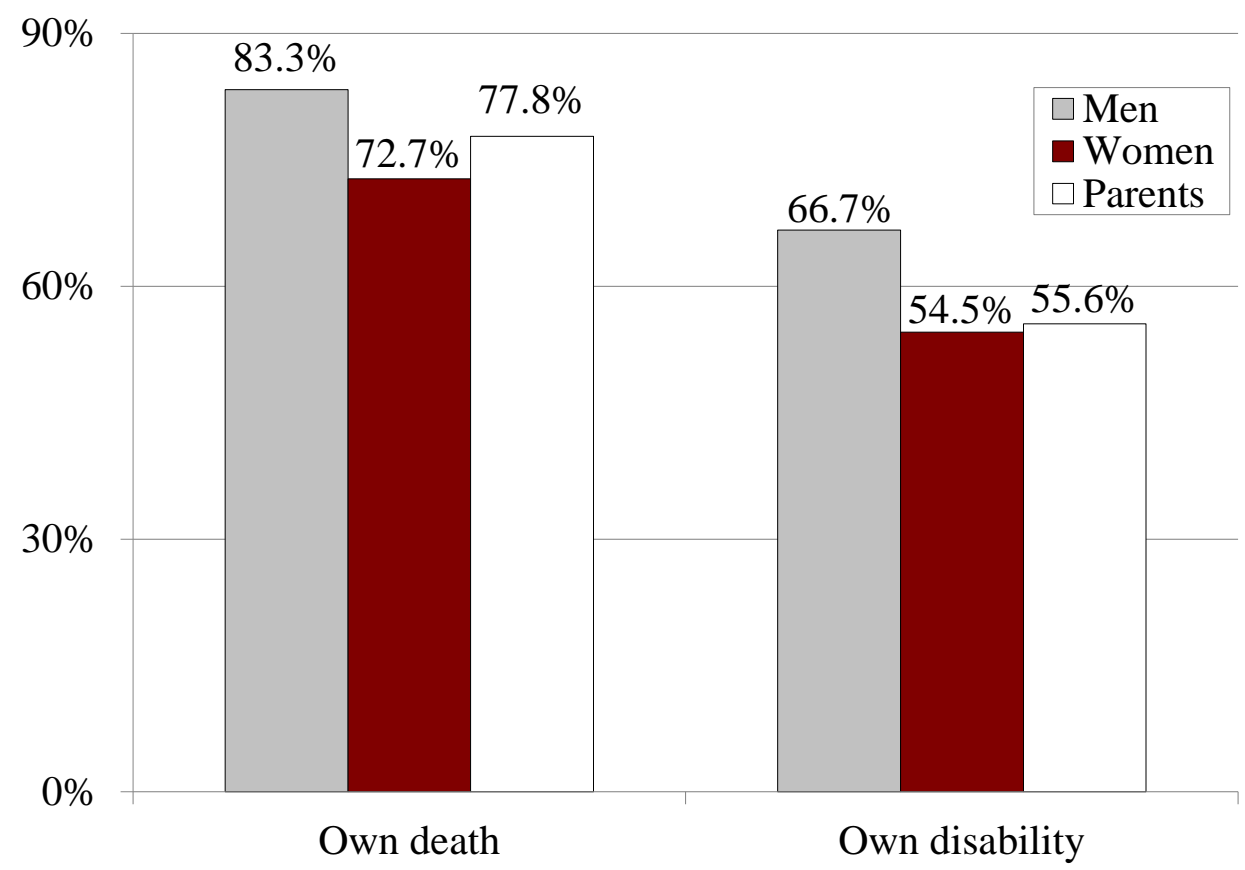

Figure 6. Disability Insurance: Interest in Potential Features

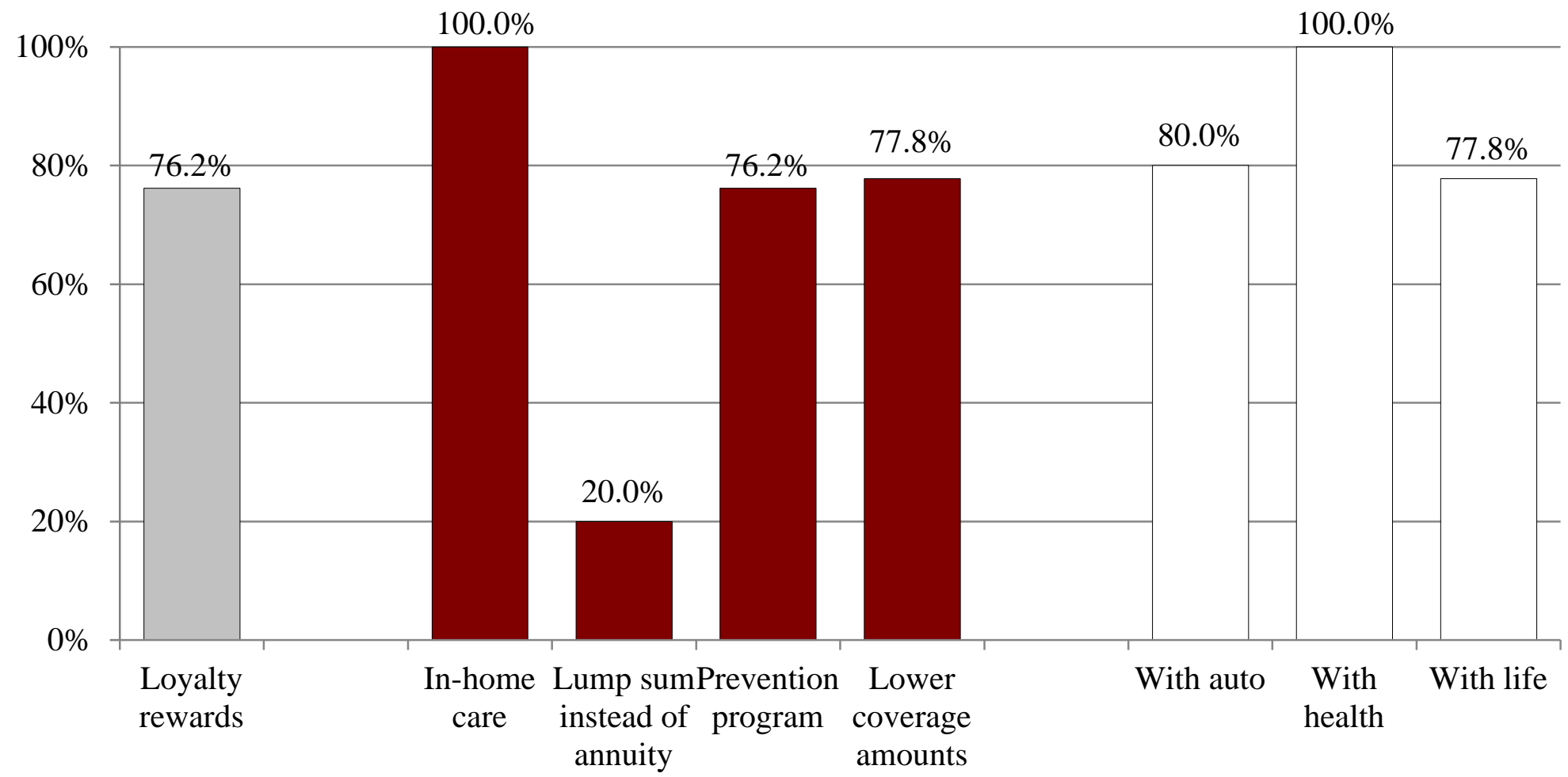

Price

Benefit framing

Bundling 


\section{Appendix.}

Interview Script

\section{Life and Disability In-Depth Interview Guide}

Hello. My name is and I am calling from Mathew Greenwald \& Associates in Washington, D.C. May I please speak to ? [READ NAME FROM RECRUITMENT.]

As you know, we are conducting a survey on behalf of Boston College's Center for Retirement Research. The purpose of the survey is to learn more about peoples' experiences with the employee benefits they can purchase at work.

As our recruiter told you, we will send you a $\$ 25$ honorarium if you complete this interview. The interview should take about 50 minutes to complete.

[ASK PERMISSION TO RECORD] Your responses will be confidential, and your name will not be connected with your specific responses. However, it is very helpful for us, for our notetaking purposes, if we can record our conversation. Only researchers will have access to the records, and they will be destroyed after 1 year. May I record our conversation?

Do you have any questions before we get started? You can stop me at any time and ask questions. Some of the questions address issues of disability and mortality, which you may find uncomfortable. You can refuse to answer questions or stop the survey at any time. This would have no impact on your current or future relationship with Boston College.

If you have no questions, we can begin. Do you give your consent to participate in this study?

\section{Background Questions}

1. To confirm, are you married? Counting your spouse and any children, how many people are financially dependent on your income?

2. Which of the following best describes the total amount of your household assets?

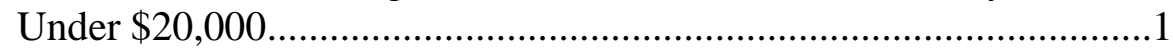

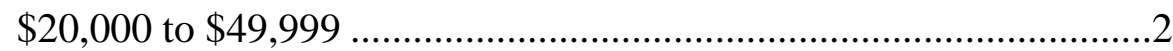

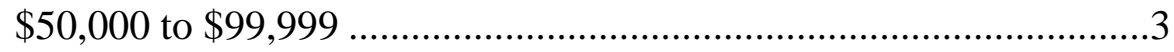

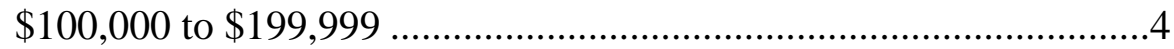

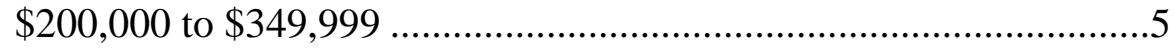

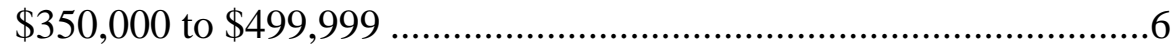

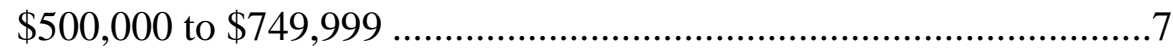

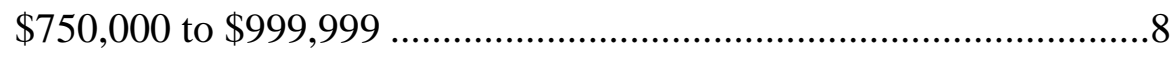

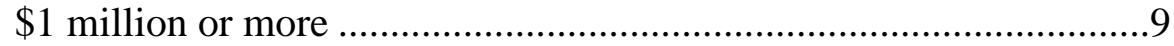

[VOL] Don’t know/Refused...........................................................10 
3. I wanted to verify that your employer offers you the opportunity to buy life insurance and/or disability insurance? Is it standalone coverage or an additional benefit to what is already offered at no cost?

$\begin{array}{ll}\text { Life only: } & \\ \text { Disability only: } & \\ \text { Both: } & \\ \text { Neither: } & \end{array}$

4. And to confirm what our recruiter asked you, which of these products have you purchased through work? When did you first purchase these?

Life only:

Disability only:

Both:

Neither:

5. Do you or your spouse have any other type of life or disability insurance?

- What are the sources of your life/disability insurance coverage?

- [IF HAVE LIFE or DISABILITY] How big a chunk of your total life/disability insurance coverage comes from the coverage you purchased at work?

6. How would you describe your financial situation/management? Do you live paycheck-topaycheck or have a rainy-day-fund to get you through tough times?

7. With your health and auto insurance policies, do you tend to get the most thorough coverage you can or do you tend to save money on premiums by having high deductibles? (Probe for specifics.)

Do you feel you have enough auto/homeowners coverage? Why/why not?

\section{Life Insurance}

Now I want to ask you some questions about your LIFE INSURANCE coverage.

8. How often do you think about whether your life insurance coverage is adequate? Do you feel that it is adequate? How did you figure this out?

9. How do/would you budget for life insurance?

Probe: Do you:

- Figure out how much you need and buy it from your employer?

- Pay for other expenses first and use what's left over? (if yes, which expenses?)

- Buy what you can get for a specific dollar amount you have in mind?

- Other approaches? 
10. [SKIP IF NO DEPENDENTS] How concerned are you that you might die while your family is still financially dependent on you?

- Do you feel like you're more or less likely to die compared to other people your age? why?

- How would your family manage financially if you were to die prematurely?

- Would this be catastrophic or manageable, financially speaking?

Probe: What concerns you most?

o Adequate income to pay the monthly bills?

o Paying off debt?

o Paying for college?

o Paying for your/your spouse's retirement?

o Maintaining current lifestyle?

o What existing insurances do you think would help?

11. Do you know what kind of coverage other's like you have, or what experts recommend for people in your situation? Do you care?

\section{Purchasing Life Insurance through Work}

12. I want to ask you about how your employer introduced the life insurance coverage and how you made your decision.

- Who introduced it -- an outside agent or an HR person? Did you trust their advice?

- How much time did you spend evaluating it? Did you seek any advice about it - if so, from whom/what sources?

- [IF PURCHASED] Was it easy or hard to sign-up? Did you have enough information and support?

- Do you think that the life insurance offered at work was reasonably priced? What makes you think this?

- Overall, what do you think of the way your employer handled the introduction of the life insurance benefit you could purchase? What would you do to make the process better?

13. [IF PURCHASED] Why did you choose to buy life insurance at work? Probe:

- What are some features or terms of your policy that you find valuable? How important are features like convenience, payroll deduction, and the ability to continue your coverage after you leave your employer?

- What type of medical questions or testing is required to qualify for the coverage? Is it easy or hard to qualify? 
14. [IF NOT PURCHASE] Why didn't you buy the insurance that was offered at work? Probe:

- Was it because you couldn't afford it or that you got better coverage elsewhere?

- Were there specific concerns that you had with the coverage - cost, limits, insurability?

- [If did not get around to it/didn't think needed it] Did you perceive it would take a long time? Why don't you believe you need disability income insurance? Was there anything your employer/the provider could have done to help you overcome procrastination?

\section{Life Insurance Options [SKIP SECTION IF HAVE BOTH VOL. LI AND DI AND TIME IS} SHORT]

15. Now I want to talk a little more about the death benefit that life insurance pays out. Think of how your family will use this money.

- [IF PURCHASED] What will your benefits pay for?

- Would it be easier for your family to meet their financial needs if they received a one-time payment or if they received a regular monthly income for a fixed period (say 10 or 20 years)?

o Would it be easier for you to estimate how much life insurance to get if you could pick the payout to be a monthly amount for a period of years or a onetime payment?

- Would it be easier for your family to meet their financial needs if they could pay off concrete items with the death benefit? For example, big ticket item like a mortgage, a kid's college education, or other loans you might want to pay off.

o Would it be easier for you to estimate how much life insurance to get if you could pick the items you'd want them to be able to pay off?

o [IF DEPENDENTS/SPOUSE] What do you think of the idea of being able to purchase life insurance with your college and retirement savings plans to ensure that your children's college or your spouse's retirement savings continue after you die?

16. Life insurance policies can offer other features. Are any of the following features appealing to you?

- Benefits for staying insured with your provider - like credit card rewards or loyalty discounts.

- Financial counseling for survivors.

\section{DISABILITY INSURANCE}

17. How often do you think about whether your long-term disability insurance coverage is adequate? Do you feel like it is enough? How did you figure this out? 
18. How do/would you budget for disability insurance? (probe) Do you:

- Figure out how much you need and buy it from your employer?

- Pay for other expenses first and use what's left over? (if yes, which expenses?)

- Buy what you can get for a specific dollar amount you have in mind?

- Other approaches?

- [If Applicable] Why is this different from Life Insurance?

19. [SKIP IF NO DEPENDENTS] How concerned are you that you might become unable to work due to a disability while your family is still financially dependent on you?

- Do you feel like you're more or less likely to become disabled compared to other people your age? Why?

20. What would you do if you were to become disabled and unable to work? How would you [and your family] manage financially?

- Would this be catastrophic or manageable, financially speaking?

Probe: What concerns you most?

o Adequate income to pay the monthly bills?

o Paying off debt?

o Paying for college?

o Paying for your/your spouse's retirement?

o Maintaining current lifestyle?

o What existing insurances do you think would help?

21. Do you know what kind of coverage other's like you have, or what experts recommend for people in your situation? Do you care?

Purchasing Disability Insurance through Work

22. I want to ask you more about how your employer introduced the disability insurance coverage.

- Who introduced it -- an outside agent or an HR person? Did you trust their advice?

- How much time did you spend evaluating the insurance? Did you seek any advice about it - if so, from whom/what sources?

- [IF PURCHASED] Was it easy or hard to sign-up? Did you have enough information and support?

- Do you think that the disability insurance offered at work was reasonably priced? What makes you think this?

- Overall, what do you think of the way your employer handled the introduction of the disability insurance benefit you could purchase? What would you do to make the process better? 
23. [IF PURCHASED] Why did you choose to buy disability insurance at work?

Probe:

- How important were features like the replacement percentage, limits, ease of getting coverage, claims process, covered disabilities, portability, definition of disability, or the convenience of payroll deduction? Any other important features or terms of your policy?

- What type of medical questions or testing is required to qualify for the coverage? Is it easy or hard to qualify?

24. [IF NOT PURCHASE] Why didn't you buy the disability insurance that was offered at work?

Probe:

- Was it because it was too expensive or that you got better coverage elsewhere?

- Were there specific concerns that you had with the coverage - cost, limits, insurability?

- [If did not get around to it/didn't think needed it] Did you perceive it would take a long time? Why don't you believe you need disability income insurance? Was there anything your employer/the provider could have done to help you overcome procrastination?

Disability Insurance Options [SKIP SECTION IF HAVE BOTH VOL. LI AND DI AND TIME IS SHORT]

25. Now I want to talk a little more about the best way to talk about disability coverage in general.

- [IF PURCHASED] What will your benefits pay for?

- Would you prefer to insure against the possibility of general disability or buy insurance to cover specific events such as cancer, accidents, loss of limbs, heart attacks, back or neck injuries? Does listing specific covered disabilities and illness help? Why or why not?

- One way to describe disability coverage is in terms of replacing a percent of monthly pay. Another way is to think of paying off specific liabilities - like a mortgage. Do you find this way more or less appealing than as a percent of pay?

- Would it be more appealing if you could choose a coverage amount other than $60 \%$ or $70 \%$ of pay? For example, $10 \%, 20 \%$ or $30 \%$ of pay to "top off" income from other sources?

- Is it better to frame it as a way to get back on your feet or support for a lifetime of disability?

- Is it better to frame it as a standalone benefit or one that you can use in conjunction with savings, workers comp, state benefits, and Social Security disability? 
26. Disability insurance policies can offer other features. Are any of the following features appealing to you?

- Prevention/risk assessment programs

- Rewards for staying insured with the same company - like credit card rewards or loyalty discounts.

- The option to get in-home care if you require it.

27. What do you think of the idea of being able to purchase disability insurance together with...?

- ...auto insurance to cover any disability that may result from an accident?

- ...health insurance to cover any disability that may result from a disease?

- ...retirement and college savings plan to ensure your contributions continue in case you're disabled?

- ... life insurance as a "complete income insurance" plan?

[Collect name and payment information. Available charities include Salvation Army, ASPCA, and American Heart Association.]

Thank you for your time and input. This has been an informative call. 


\section{RECENT WORKING PAPERS FROM THE CENTER FOR RETIREMENT RESEARCH AT BOSTON COLLEGE}

What Do Subjective Assessments of Financial Well-Being Reflect?

Steven A. Sass, Anek Belbase, Thomas Cooperrider, and Jorge D. Ramos-Mercado, March 2015

The Impact of Leakages from 401(k)s and IRAs

Alicia H. Munnell and Anthony Webb, February 2015

Recruiting and Retaining High-Quality State and Local Workers: Do Pensions Matter? Alicia H. Munnell, Jean-Pierre Aubry, and Geoffrey T. Sanzenbacher, January 2015

Do Tax Incentives Increase 401(k) Retirement Saving? Evidence from the Adoption of Catch-Up Contributions

Matthew S. Rutledge, April Yanyuan Wu, and Francis M. Vitagliano, November 2014

Are Retirees Falling Short? Reconciling the Conflicting Evidence

Alicia H. Munnell, Matthew S. Rutledge, and Anthony Webb, November 2014

Lifetime Job Demands, Work Capacity at Older Ages, and Social Security Benefit Claiming Decisions

Lauren Hersch Nicholas, November 2014

Who Is Internationally Diversified? Evidence from 296 401(k) Plans

Geert Bekaert, Kenton Hoyem, Wei-Yin Hu, and Enrichetta Ravina, November 2014

The Causes and Consequences of Financial Fraud Among Older Americans

Keith Jacks Gamble, Patricia Boyle, Lei Yu, and David Bennett, November 2014

New Evidence on the Risk of Requiring Long-Term Care

Leora Friedberg, Wenliang Hou, Wei Sun, Anthony Webb, and Zhenyu Li, November 2014

SSI at 62: Protecting the Vulnerable When Increasing Social Security's Early Entitlement Age

Norma B. Coe and April Yanyuan Wu, June 2014

Why Do SSI and SNAP Enrollments Rise in Good Economic Times and Bad?

Matthew S. Rutledge and April Yanyuan Wu, June 2014

The Impact of Mandatory Coverage on State and Local Budgets

Alicia H. Munnell, Jean-Pierre Aubry, and Anek Belbase, May 2014

All working papers are available on the Center for Retirement Research website

(http://crr.bc.edu) and can be requested by e-mail (crr@bc.edu) or phone (617-552-1762). 